\title{
Equity of inpatient health care in rural Tanzania: a population- and facility-based survey
}

\author{
Grace A Ferry ${ }^{1 *}$, Sean R Dickson², Godfrey Mbaruku ${ }^{3}$, Lynn P Freedman ${ }^{4}$ and Margaret E Kruk ${ }^{5}$
}

\begin{abstract}
Objective: To explore the equity of utilization of inpatient health care at rural Tanzanian health centers through the use of a short wealth questionnaire.

Methods: Patients admitted to four rural health centers in the Kigoma Region of Tanzania from May 2008 to May 2009 were surveyed about their illness, asset ownership and demographics. Principal component analysis was used to compare the wealth of the inpatients to the wealth of the region's general population, using data from a previous population-based survey.

Results: Among inpatients, 15.3\% were characterized as the most poor, 19.6\% were characterized as very poor, $16.5 \%$ were characterized as poor, $18.9 \%$ were characterized as less poor, and $29.7 \%$ were characterized as the least poor. The wealth distribution of all inpatients $(p<0.0001)$, obstetric inpatients $(p<0.0001)$, other inpatients $(p<$ 0.0001), and fee-exempt inpatients ( $p$ 0.001) were significantly different than the wealth distribution in the community population, with poorer patients underrepresented among inpatients. The wealth distribution of pediatric inpatients $(p=0.2242)$ did not significantly differ from the population at large.

Conclusion: The findings indicated that while current Tanzanian health financing policies may have improved access to health care for children under five, additional policies are needed to further close the equity gap, especially for obstetric inpatients.
\end{abstract}

\section{Introduction}

Although government expenditures for health in lowand middle-income countries are intended to ensure access to health care for the poor, they frequently disproportionately benefit wealthier citizens $[1,2]$. A review of public expenditures on health in 26 developing countries found that the poorest fifth of a population typically received less than a fifth of government expenditures on health [3]. Another study published by O'Donnell and colleagues found that the concentration index of public health spending-a measure of the wealth distribution of spending-in Asia was pro-rich in 7 of the 11 countries/regions studied: Nepal, Bangladesh, Indonesia, India, Vietnam, and Gansu and Heilongjiang provinces in China [4]. The most pro-rich financing was found in Nepal, the poorest country.

\footnotetext{
* Correspondence: gferry@mathematica-mpr.com

'Mathematica Policy Research $11001^{\text {st }}$ Street Northeast Washington, DC 20011 USA

Full list of author information is available at the end of the article
}

User fees, or out-of-pocket payments, at the point of care are used extensively to raise revenues in many poor countries. Researchers have established that user fees contribute to inequities by decreasing the use of needed health services by the poor and near-poor [5-7]. Informal or illegal fees and other costs, such as transportation expenses, also contribute to inequities by making health care unaffordable for poorer individuals [8-11].

Several studies have indicated that removing user fees can reduce, although not eliminate, barriers to access $[12,13]$. For example, a study in Ghana found that while removing user fees for deliveries helped to narrow the equity gap for deliveries at facilities, other costs-such as transportation expenses-remained substantial and meant that the wealthy were more likely to deliver in a health facility than their poorer counterparts [14].

Tanzania, a low-income country in East Africa, removed user fees for maternal and child (under-5) health services, as well as fees for individuals over age 60 and those with specific medical conditions (e.g, HIV, TB) as part of an effort to promote equitable utilization 
of essential health care. While there is evidence that the exemptions have not eliminated wealth-based disparities in access to outpatient and obstetric delivery services, there is less information about the equity of inpatient services $[10,15,16]$. As inpatient services address more serious conditions, inequitable utilization across socioeconomic status may have important health consequences.

One approach to assessing equity of inpatient admissions is a wealth comparison between inpatients and the general population. This has been done by researchers in Bangladesh who demonstrated that a simplified wealth asset patient questionnaire can be applied in a low-income hospital to study equity in access to emergency obstetric care [17].

The objective of this study was to explore the equity of utilization of maternal, child, and other adult inpatient health care in Tanzania. We used a short admission questionnaire that contained information on household assets-a measure of permanent income-and compared the wealth distribution of inpatients to that of the surrounding communities, using data from a previous population-based survey. We were particularly interested in comparing equity of utilization of fee-exempt and non fee-exempt services. We also wanted to qualitatively assess the feasibility of such an approach for ongoing monitoring of equitable health service provision in a low-income country. To our knowledge, this is the first application of this approach in Africa.

\section{Methods}

\section{Study setting}

Data was collected at four rural health centers (Bitale, Nguruka, Kakonko, and Mabamba) in Tanzania's Kigoma Region, a western region bordering Burundi and separated from the Democratic Republic of Congo by Lake Tanganyika. Bitale and Nguruka are located in the Kigoma Rural district and Kakonko and Mabamba are located in Kibondo district. Nguruka, Kakonko, and Mabamba are all receiving new staff houses and operating theaters as part of health facility upgrades. Facility and patient level data were collected for four months, May 2008, September 2008, January 2009, and May 2009. The data collected is part of a larger study to prospectively assess the impact of quality upgrades in three health centers (plus one comparison health center without upgrades) on overall maternal health care utilization in the Kigoma Region of Tanzania.

The health centers provide both primary and secondary care. The user fee to receive inpatient services was $2,000 \mathrm{TZS}$ or $1.50 \mathrm{USD}$. In 2002, the gross national income per capita was $\$ 290$ [18]. User fee exemptions are provided to the following: individuals under the age of five or over the age of sixty, pregnant mothers (e.g., deliveries, antenatal care, and postnatal care), and individuals with exempt medical conditions (e.g., HIV/ AIDS, tuberculosis, diabetes, and cancer) [19]. The health centers also accept national health insurance, health benefits for government employees, and community fund insurance, a national prospective payment program that costs 5,000 TZS or 3.75 USD per year and covers services for an individual and their immediate family at dispensaries and health centers (catastrophic expenses are excluded) [19].

\section{Facility-level data}

Project managers collected facility-level data at the beginning and end of each monthly data collection period. Facility-level data tracked included facility inputs (e.g., staffing levels, functionality of equipment, training courses offered, and progress on health center upgrades) and facility outputs (e.g., total admissions and length of stay).

\section{Patient level data collection}

The patient survey and consent form were developed in English, translated into Swahili, and then back translated. The one-page questionnaire included demographic characteristics, admission diagnosis, self-reported health status, and asset ownership. The survey assessed household ownership of 10 assets: bike, radio, fowl, phone, electricity, mosquito nets, house material, type of toilet, number of rooms for sleeping, and meals eaten per day. These were selected from a previous population-based study of 1,205 women in the same region completed in July of 2007, the details of which are described elsewhere [20].

Two health workers from each health center were trained to administer the survey. Following the September 2008 data collection period, one trained interviewer from Bitale was transferred to another health center and the other trained interviewer left the post for personal reasons. The two replacement health workers were trained by the project manager and completed interviews in January 2009 and May 2009.

All patients who were admitted to the four health centers were eligible to participate after providing written consent. The parents/guardians of inpatients under the age of 18 provided consent on their children's behalf. If patients were severely ill on admission, study health workers were instructed to interview them only after their conditions stabilized. Patient interviews lasted for approximately 5-10 minutes. Written consent was obtained from all participants. The study received ethical clearance from the Tanzania National Institute for Medical Research and the University of Michigan Institutional Review Board.

\section{Statistical analysis}

We calculated univariate statistics for health center characteristics and demographic variables for all 
admissions, as well as three admission sub-types: pediatric admissions, obstetric admissions, and other admissions. Individuals under the age of 5 were classified as pediatric admissions. Individuals admitted for deliveries, post-delivery complications, or post-abortion complications were classified as obstetric admissions. Marital status was assessed for adult inpatients. Previous schooling was only assessed for inpatients at least 7 years old.

Inpatients were categorized into wealth groups (quintiles) based on their asset index using population quintile cut-offs in the Kruk et al population-based survey [20]. Asset indices are frequently used to estimate permanent wealth in non-cash economies [21]. Household assets were assigned numeric values and an index was created using principal component analysis. The first component was used to determine asset weights, which were then used to calculate a continuous index of wealth [21-23]. Based on the value for the asset index, households were divided into five wealth quintiles (quintile 1 was designated as poorest and quintile 5 the richest). Individuals missing more than one asset response were not included in the wealth analysis. Assets were imputed for individuals with only one asset response missing, using logit imputation for the dichotomous assets and mean imputation for the number of mosquito nets and daily meals. A bivariate analysis comparing patients excluded from equity analysis to those classified by wealth quintile was completed, showing no meaningful differences between the two groups on demographic and illness factors.

Concentration curves were constructed and concentration indices were calculated for all inpatients and the three admission sub-types. Concentration curves indicate the equity of distribution of a service graphically. Concentration curves have ascending wealth on the $x$ axis and a health variable on the $y$-axis, with a 45-degree line indicating equitable distribution and values below this line indicating disproportionate concentration of the variable among the rich. Concentration indices were also calculated for the following subgroups: patients with fee exempt status and patients required to pay a fee. The concentration index is a quantitative measure of the deviation of the concentration curve from the line of equality (45 degrees) and has been widely used in international research to quantify the degree of income inequality [24-27]. A concentration index of zero indicates perfect equity. Since admissions are a health good, concentration curves falling below the line of equity indicate a system that disproportionately benefits the wealthier individuals-i.e., where admissions are more frequent for the wealthy. A larger concentration index indicates greater inequity.

A Wilcoxon rank-sum test was completed comparing the wealth distribution of all inpatients, as well as the defined subgroups, to the wealth distribution of the community population. The same test was performed to compare the wealth distribution of the subgroups to wealth distribution of all inpatients.

\section{Results}

Table 1 summarizes the characteristics of the four health centers. Over the four month period, the mean number of health workers at each clinic ranged from 1.5 to 2.8 for assistant medical officers and clinical officers, mid-level health providers who can engage in limited diagnostics and prescribing, and from 2.5 to 6.3 for nurses and midwives. No physicians were on staff for any of the health centers. The mean number of beds over this period ranged from 22.8 to 39.8 .

In May 2008, September 2008, January 2009, and May 2009, 2,767 patients were admitted to the four health centers. 2,578, or $93.2 \%$, of inpatients participated in the study. The number of participants recruited from Kakonko, Bitale, Mabamba, and Nguruka are 976, 565, 554 , and 483 , respectively.

Table 2 describes the characteristics of all admissions and the following sub groups: pediatric admissions, obstetric admissions, and other admissions. One health center worker from Bitale recorded the age of the parent or guardian instead of the age of the child when completing the interview on the child's behalf. As a result, the data from Bitale was not included in the subgroup analysis. For the population as a whole, $24.2 \%$ of inpatients were under the age of 5 and $84.2 \%$ of inpatients were under the age of 36 . The majority of inpatients (78.7\%) were female. Of the inpatients older than the legal age of marriage -15 for females and 18 for males $-57.8 \%$ were currently married. Of the inpatients 7 years and older, $25.2 \%$ of inpatients had not attended any school. Eightyone percent of inpatients described their health status as good or very good. The majority of patients walked to the clinic (50.3\%). The most common reasons for admission were malaria $(39.3 \%)$, delivery $(32.0 \%)$, respiratory infection (9.7\%), and diarrhea or dysentery (5.2\%).

Table 3 describes the wealth distribution and concentration index of all admissions and the aforementioned subgroups. For all inpatients, 15.3\% were characterized as the most poor, $19.6 \%$ were characterized as very poor, $16.5 \%$ were characterized as poor, $18.9 \%$ were characterized as less poor, and $29.7 \%$ were characterized as the least poor. Figure 1 displays the concentration curves for these groups. For all admissions and for each subgroup the concentration curve falls below the fortyfive degree line, indicating wealth-based inequality. The concentration index for all admissions was 0.1128 . The concentration indices for the pediatric, obstetric, and other admissions were $0.0472,0.1460$, and 0.1385 , respectively. 
Table 1 Characteristics of four rural health centers in Kigoma, Tanzania over four months ${ }^{1}$

\begin{tabular}{|c|c|c|c|c|}
\hline & Bitale & Kakonko & Mabamba & Nguruka \\
\hline \multicolumn{5}{|l|}{ Number of health workers $^{2}$} \\
\hline physicians & 0 & 0 & 0 & 0 \\
\hline assistant medical officers and clinical officers ${ }^{3}$ & 2.3 & 1.5 & 1.8 & 2.8 \\
\hline nurses and midwives & 3.3 & 2.5 & 3.3 & 6.3 \\
\hline Beds ${ }^{2}$ & 22.8 & 39.8 & 36.5 & 24.5 \\
\hline
\end{tabular}

${ }^{1}$ Data was collected in May 2008, September 2008, January 2009, and May 2009.

2 The health workers and the number of beds are averaged over the four month period.

${ }^{3}$ Assistant medical officers and clinical officers are mid-level health providers who can engage in limited diagnostics and prescribing

When comparing the ordinal wealth quintiles using Wilcoxon rank sum tests, the wealth distribution of all inpatients $(p<0.0001)$, obstetric inpatients $(p<0.0001)$, other inpatients $(\mathrm{p}<0.0001)$, and fee-exempt inpatients $(\mathrm{p}<$ 0.001 ) were significantly different than the wealth distribution in the community population. The wealth distribution of pediatric inpatients $(\mathrm{p}=0.2242)$ did not significantly differ from the population at large. The analyses with continuous asset index had similar results.

To address potential misclassification between single quintiles, we analyzed admissions for the poorest $40 \%$ of the population (grouping together quintiles 1 and 2) and the richest $40 \%$ (grouping together quintiles 4 and 5) of the population. The richest $40 \%$ of the population accounted for $48.6 \%$ of admissions whereas the poorest $40 \%$ of the population accounted for $35.2 \%$ of admissions.

\section{Discussion}

This study assessed the wealth distribution of inpatients admitted to rural health centers in Tanzania to provide insight about equity of inpatient care in Tanzania under current fee exemption policies. We found that in Kigoma Region, Tanzania, wealthier citizens were more likely to use rural health centers for inpatient care than their poorer counterparts. Overall, the richest $20 \%$ of the population accounted for $29.7 \%$ of admissions to the rural health centers whereas the poorest $20 \%$ of the population accounted for only $15.3 \%$ of admissions. Admissions were inequitable for obstetric inpatients and other adult inpatients in which the poorest $20 \%$ of the population accounted for $11.6 \%$ and $16.8 \%$ of inpatients, respectively. Inequities were not found for the pediatric inpatients.

The finding that individuals in the wealthiest quintile use health center services at a disproportionately high rate is consistent with other research on inequities $[1,28,29]$. This study also supports prior research findings that user fee exemptions increase equity but are, by themselves, insufficient to eliminate wealth-based inequities. For fee exempt individuals, the richest $20 \%$ of the population accounted for $27.1 \%$ of admissions, as compared to $34.6 \%$ for patients required to pay a fee.
Informal fees, transportation expenses, or potential lost wages for family members may account for remaining inequities. For example, in a study conducted in the same region of Tanzania, Kruk and colleagues found that, on average, deliveries at a government facility cost women 6268 TZS (approximately 4.20 USD), despite the fee-exempt status for obstetric admissions. Approximately half of delivery costs could be attributed to transportation costs and the remainder to illegal provider fees or fees for supplies [10]. These expenses may not only result in lower utilization by fee-exempt patients, but also result in greater economic hardship for poorer patients as compared to richer patients who use the health centers. Prior research suggests that inpatients in the poorest wealth quintiles may be more likely to reduce expenditures for other goods, such as food, or to borrow or sell items to afford care [30,31].

The relatively larger inequities observed within the obstetric admission group, as compared to the pediatric admission group (both groups fall in the fee exempt category), may indicate that transportation expenses and informal fees are a greater barrier to care for obstetric patients. Fees for drugs and supplies may be particularly high for obstetric admissions since they often involve more complicated procedures and medicines and supplies which may not be routinely available at health centers and thus must be purchased by patients. Similarly, transportation fees for obstetric emergencies may be higher as they may require private transport at night and in bad weather to a greater extent than other admissions. Other factors, such as education and preferences for formal health care, that differ between poorer and richer women, may also limit poor women's demand for facility-based obstetric are [20,32].

This study compared the results of a patient questionnaire to the results of a population-based survey. Each admitted patient completed a 5-10 minute survey with questions on demographics and a 10-question asset index. The high response rate (93.2\%) as well as debriefings of the health workers administering the survey confirming that the questionnaire did not interfere with patient care, suggest that this method is feasible for 
Table 2 Characteristics of inpatients at four rural health centers in Kigoma, Tanzania over a four month period $^{1}$ $\left(n=2578^{2}\right)$

\begin{tabular}{|c|c|c|c|c|c|c|c|c|c|c|}
\hline & \multicolumn{2}{|c|}{$\begin{array}{l}\text { All admissions } \\
(\mathrm{n}=2578)\end{array}$} & \multicolumn{2}{|c|}{$\begin{array}{l}\text { Pediatric } \\
\text { admissions }{ }^{3}, \\
(n=485)\end{array}$} & \multicolumn{2}{|c|}{$\begin{array}{l}\text { Obstetric admissions }{ }^{4} \\
(n=823)\end{array}$} & \multicolumn{2}{|c|}{$\begin{array}{l}\text { Other adult admissions* } \\
(\mathrm{n}=806)\end{array}$} & \multicolumn{2}{|c|}{$\begin{array}{l}\text { Fee-exempt admissions* } \\
(\mathrm{n}=1241)\end{array}$} \\
\hline & $n$ & (\%) & $\mathrm{N}$ & $(\%)$ & $\mathrm{n}$ & $(\%)$ & $\mathrm{n}$ & (\%) & $\mathrm{n}$ & (\%) \\
\hline \multicolumn{11}{|l|}{ Age } \\
\hline$<5$ & $485^{*}$ & $(24.2)$ & 485 & $(100.0)$ & 0 & $(0.0)$ & 0 & $(0.0)$ & 485 & $(39.2)$ \\
\hline $5-17$ & $149^{*}$ & $(7.4)$ & 0 & $(0.0)$ & 39 & $(4.8)$ & 116 & $(14.5)$ & 34 & $(2.8)$ \\
\hline $18-25$ & $591^{*}$ & $(29.5)$ & 0 & $(0.0)$ & 399 & $(48.7)$ & 238 & $(29.8)$ & 351 & $(28.4)$ \\
\hline $26-35$ & $462^{*}$ & $(23.1)$ & 0 & $(0.0)$ & 296 & $(36.1)$ & 208 & $(26.0)$ & 249 & $(20.1)$ \\
\hline$>35$ & $317^{*}$ & $(15.8)$ & 0 & $(0.0)$ & 85 & $(10.4)$ & 238 & $(29.8)$ & 119 & $(9.6)$ \\
\hline Female & 2023 & $(78.7)$ & 266 & $(55.0)$ & 823 & $(100.0)$ & 585 & $(72.8)$ & 1000 & $(80.7)$ \\
\hline Currently married ${ }^{5}$ & $828^{*}$ & $(57.8)$ & 0 & $(0.0)$ & 499 & $(61.3)$ & 402 & $(55.8)$ & 447 & $(59.9)$ \\
\hline No schooling ${ }^{6}$ & $370^{*}$ & $(25.2)$ & 0 & $(0.0)$ & 174 & (21.9) & 209 & (27.3) & 187 & $(25.4)$ \\
\hline Very good or good health status & 2078 & $(81.0)$ & 402 & $(84.3)$ & 717 & $(87.4)$ & 819 & (76.3) & 1044 & $(84.9)$ \\
\hline \multicolumn{11}{|l|}{ Transportation to clinic } \\
\hline walked & 1292 & $(50.3)$ & 251 & $(51.9)$ & 411 & $(50.0)$ & 282 & $(35.2)$ & 585 & $(47.2)$ \\
\hline biked & 810 & $(31.5)$ & 158 & $(32.6)$ & 254 & $(30.9)$ & 317 & (39.6) & 423 & $(34.1)$ \\
\hline \multicolumn{11}{|l|}{ Reason for admission } \\
\hline Malaria & 985 & $(39.3)$ & 280 & $(60.0)$ & 0 & $(0.0)$ & 415 & $(54.3)$ & 292 & $(23.7)$ \\
\hline Delivery & 802 & $(32.0)$ & 0 & $(0.0)$ & 773 & $(93.9)$ & 0 & $(0.0)$ & 4 & $(0.3)$ \\
\hline Respiratory infection & 242 & $(9.7)$ & 93 & $(19.9)$ & 0 & $(0.0)$ & 101 & $(13.2)$ & 106 & $(8.6)$ \\
\hline Diarrhea/dysentery & 130 & $(5.2)$ & 57 & $(12.2)$ & 0 & $(0.0)$ & 24 & $(3.1)$ & 57 & $(4.6)$ \\
\hline Accident/injury & 82 & (3.3) & 5 & $(1.1)$ & 0 & $(0.0)$ & 70 & $(9.2)$ & 6 & $(0.5)$ \\
\hline Acute abdominal pain & 61 & $(2.4)$ & 2 & $(0.4)$ & 0 & $(0.0)$ & 45 & $(5.9)$ & 3 & $(0.2)$ \\
\hline Abortion & 24 & $(1)$ & 0 & $(0.0)$ & 24 & $(2.9)$ & 0 & $(0.0)$ & 21 & $(1.7)$ \\
\hline Anemia & 28 & $(1.1)$ & 9 & $(1.9)$ & 0 & $(0.0)$ & 15 & (2) & 9 & $(0.7)$ \\
\hline Post-delivery complication & 27 & $(1.1)$ & 1 & $(0.2)$ & 26 & $(3.2)$ & 0 & $(0.0)$ & 7 & $(0.6)$ \\
\hline Poison/snake bite & 13 & $(0.5)$ & 3 & $(0.6)$ & 0 & $(0.0)$ & 8 & $(1.1)$ & 3 & $(0.2)$ \\
\hline Hypertension & 8 & $(0.3)$ & 0 & $(0.0)$ & 0 & $(0.0)$ & 6 & $(0.8)$ & 1 & $(0.1)$ \\
\hline Fever of unknown origin & 8 & $(0.3)$ & 2 & $(0.4)$ & 0 & $(0.0)$ & 5 & $(0.7)$ & 3 & $(0.2)$ \\
\hline Measles & 12 & $(0.5)$ & 0 & $(0.0)$ & 0 & $(0.0)$ & 12 & (1.6) & 0 & $(0.0)$ \\
\hline HIV/AIDS & 7 & $(0.3)$ & 0 & $(0.0)$ & 0 & $(0.0)$ & 6 & $(0.8)$ & 679 & $(55.2)$ \\
\hline Tuberculosis & 4 & $(0.2)$ & 0 & $(0.0)$ & 0 & $(0.0)$ & 4 & $(0.5)$ & 23 & $(1.9)$ \\
\hline Asthma & 4 & $(0.2)$ & 0 & $(0.0)$ & 0 & $(0.0)$ & 4 & $(0.5)$ & 0 & $(0.0)$ \\
\hline Urinary tract infection & 4 & $(0.2)$ & 2 & $(0.4)$ & 0 & $(0.0)$ & 0 & $(0.0)$ & 2 & $(0.16)$ \\
\hline Other & 68 & $(2.7)$ & 13 & $(2.7)$ & 0 & $(0.0)$ & 49 & (6.4) & 15 & $(1.22)$ \\
\hline
\end{tabular}

*Data for health center Bitale was omitted because one interviewer recorded the age of the parent instead of the child for pediatric admissions

${ }^{1}$ Data was collected in May 2008, September 2008, January 2009, and May 2009.

2 Totals may not equal 2578 due to missing values.

${ }^{3}$ Inpatients classified as pediatric admissions were under the age of 5.

${ }^{4}$ Inpatients classified as obstetric admissions were admitted for delivery, post-delivery complications, or post-abortion complications.

${ }^{5}$ Marital status was determined for females 15 years and older and for males 18 years and older.

${ }^{6}$ No schooling was determined for patients 7 years and older.

intermittent assessments of equity of inpatient care. While this was done as part of a formal research project, with attendant ethical clearance and scientific review processes, such approaches may be incorporated into ongoing monitoring and evaluation processes in countries. In those instances, routine population-based surveys, such as the Demographic Health Survey or National Census, can be used to determine the asset cutoffs for each quintile and to develop the brief asset tool. 
Table 3 Wealth distribution of inpatients at four rural health centers in Kigoma, Tanzania over three months ${ }^{1}$ $\left(n=2575^{2}\right)$

\begin{tabular}{|c|c|c|c|c|c|c|c|c|c|c|c|c|}
\hline & \multicolumn{2}{|c|}{$\begin{array}{l}\text { Community population } \\
\qquad(\mathrm{n}=1205)\end{array}$} & \multicolumn{2}{|c|}{$\begin{array}{c}\text { All } \\
\text { inpatients } \\
(\mathrm{n}=2575)\end{array}$} & \multicolumn{2}{|c|}{$\begin{array}{c}\text { Pediatric } \\
\text { inpatients }{ }^{3} \text {,* } \\
(\mathrm{n}=483)\end{array}$} & \multicolumn{2}{|c|}{$\begin{array}{l}\text { Obstetric } \\
\text { inpatients } \\
(\mathrm{n}=1002)\end{array}$} & \multicolumn{2}{|c|}{$\begin{array}{l}\text { Other adult inpatients* } \\
\qquad(\mathrm{n}=806)\end{array}$} & \multicolumn{2}{|c|}{$\begin{array}{l}\text { Fee-exempt inpatients* } \\
\qquad(\mathrm{n}=1238)\end{array}$} \\
\hline & $\mathrm{N}$ & (\%) & $\mathbf{n}$ & (\%) & $\mathbf{n}$ & $(\%)$ & $\mathrm{n}$ & (\%) & $\mathrm{n}$ & (\%) & $\mathrm{n}$ & (\%) \\
\hline most poor & 236 & $(19.6)$ & 393 & $(15.3)$ & 82 & $(17.0)$ & 95 & $(11.6)$ & 135 & $(16.8)$ & 181 & $(14.6)$ \\
\hline very poor & 246 & $(20.4)$ & 505 & (19.6) & 97 & $(20.1)$ & 182 & $(22.1)$ & 145 & $(18.0)$ & 266 & $(21.5)$ \\
\hline poor & 236 & $(19.6)$ & 425 & $(16.5)$ & 99 & $(20.5)$ & 129 & $(15.7)$ & 108 & $(13.4)$ & 217 & $(17.5)$ \\
\hline less poor & 246 & $(20.4)$ & 487 & $(18.9)$ & 92 & $(19.1)$ & 160 & $(19.5)$ & 142 & (17.6) & 238 & $(19.2)$ \\
\hline least poor & 241 & $(20.0)$ & 765 & $(29.7)$ & 113 & $(23.4)$ & 256 & $(31.1)$ & 276 & $(34.2)$ & 336 & $(27.1)$ \\
\hline \multicolumn{3}{|c|}{ Concentration index } & \multicolumn{2}{|c|}{0.1128} & \multicolumn{2}{|c|}{0.0472} & \multicolumn{2}{|c|}{0.1460} & \multicolumn{2}{|l|}{0.1385} & \multicolumn{2}{|l|}{0.0911} \\
\hline \multicolumn{3}{|c|}{$\begin{array}{l}\text { Chi-square of lowest two quintiles to } \\
\text { highest two quintiles }\end{array}$} & \multicolumn{2}{|c|}{$<0.0001$} & \multicolumn{2}{|c|}{0.0874} & \multicolumn{2}{|c|}{$<0.0001$} & \multicolumn{2}{|l|}{$<0.0001$} & \multicolumn{2}{|l|}{$<0.0001$} \\
\hline \multicolumn{3}{|c|}{ Wilcoxon rank sum, community population } & \multicolumn{2}{|c|}{$<0.0001$} & \multicolumn{2}{|c|}{0.2242} & \multicolumn{2}{|c|}{$<0.0001$} & \multicolumn{2}{|l|}{$<0.0001$} & \multicolumn{2}{|l|}{0.0001} \\
\hline
\end{tabular}

*Data for health center Bitale was omitted because one interviewer recorded the age of the parent instead of the child for pediatric admissions

${ }^{1}$ Data was collected in May 2008, September 2008, January 2009, and May 2009.

${ }^{2}$ Inpatients with more than one asset response missing were excluded from this analysis. For those with only one asset missing, the missing asset was imputed as described in methods, above.

${ }^{3}$ Inpatients classified as pediatric inpatients were under the age of 5 and were not admitted for obstetric conditions.

${ }^{4}$ Inpatients classified as obstetric inpatients were admitted for delivery, post-delivery complications, or post-abortion complications.

The study has several limitations. There was a twoyear interval between the population-based study and the facility study, which may have resulted in some misclassification of wealth groups if asset ownership increased substantially over this time. For example, the cost of mobile phones may have fallen and thus made these more ubiquitous among households [33]. This would lead to an under-estimate of inequities in facility

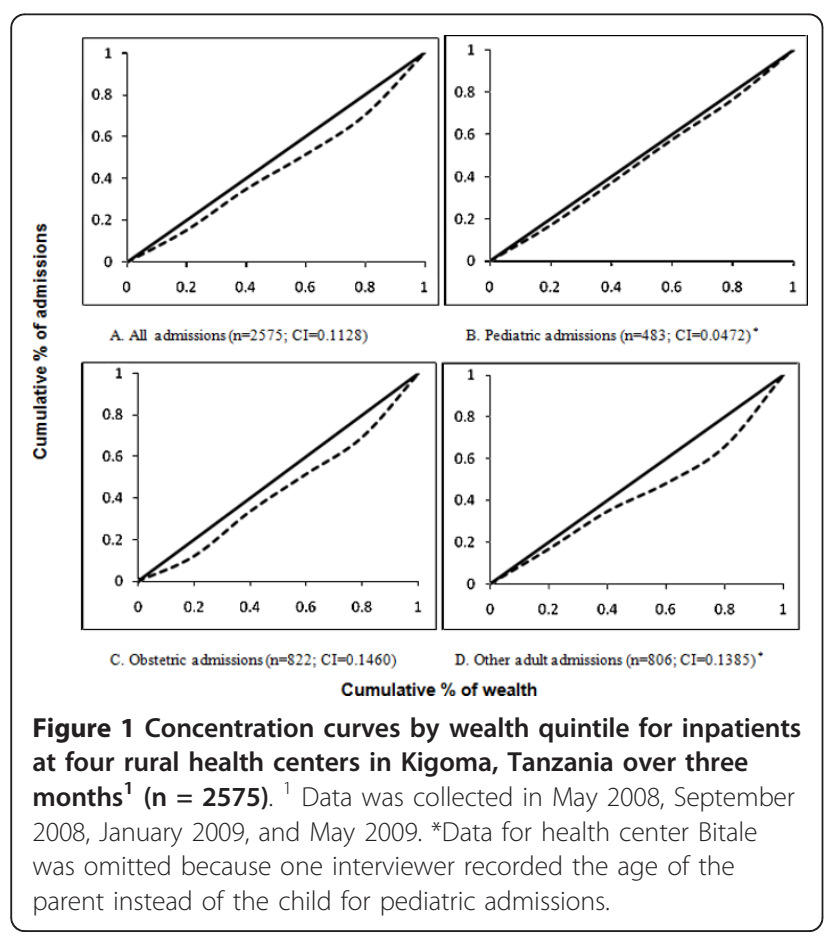

use. The focus of the study was on barriers to access to inpatient services and we did not measure financial hardship due to inpatient care. As noted above, poor families who are able to obtain care frequently face disproportionate financial burdens from the costs of care. In addition, future research should address the role of education in mitigating the effect of poverty on equity of utilization.

\section{Conclusion}

The facility-based study supports prior research on propoor health financing and indicated that the current Tanzanian health financing policies may have improved access to health care for children under five, but that additional policies are needed to further close the equity gap, especially for obstetric inpatients. The successful administration of this brief questionnaire in rural Tanzania suggests that this may be a feasible approach to monitoring the effect of health system policies on equitable provision of health care in low-income countries.

\section{Author details}

${ }^{1}$ Mathematica Policy Research $11001^{1^{\text {st }}}$ Street Northeast Washington, DC 20011 USA. ${ }^{2}$ Department of Health Management and Policy University of Michigan School of Public Health 1415 Washington Heights Ann Arbor, MI 48109 USA. ${ }^{3}$ Ifakara Health Institute Plot 463, Kiko Avenue Mikocheni P.O. Box 78373 Dar es Salaam Tanzania. ${ }^{4}$ Department of Population and Family Health Columbia University Mailman School of Public Health 60 Haven Avenue New York, NY 10032 USA. ${ }^{5}$ Department of Health Policy and Management Columbia University Mailman School of Public Health 600 West $168^{\text {th }}$ Street New York, NY 10032 USA.

\section{Authors' contributions}

GF participated in data collection, contributed to the analysis, and wrote the first draft of the manuscript. SD helped coordinate data collection, 
performed the statistical analysis, and contributed to the manuscript. GM assisted in the study design and helped revise the manuscript. LF contributed to analysis and helped revise the manscript. MK concieved of the study, oversaw data collection, and contributed to the manscript. All authors read and approved the final manuscript.

\section{Competing interests}

The authors declare that they have no competing interests.

Received: 22 August 2011 Accepted: 15 February 2012 Published: 15 February 2012

\section{References}

1. Gafar J: The benefit-incidence of public spending: the Caribbean experience. Journal of International Development 2006, 18:449-468.

2. Blas E, Limbambala M: User-payment, decentralization and health service utilization in Zambia. Health Policy Plan 2001, 16(Suppl 2):19-28.

3. Filmer D: The incidence of public expenditures on health and education. Background paper for the WDR 2004.

4. O'Donnell O, van Doorslaer E, Rannan-Eliya RP, Somanathan A, Adhikari SR, Harbianto D, Garg CC, Hanvoravongchai P, Huq MN, Karan A: The incidence of public spending on healthcare: comparative evidence from Asia. The World Bank Economic Review 2007.

5. Kipp W, Kamugisha J, Jacobs P, Burnham G, Rubaale T: User fees, health staff incentives, and service utilization in Kabarole District, Uganda. Bulletin of the World Health Organization 2001, 79:1032-1037.

6. Mbugua JK, Bloom GH, Segall MM: Impact of user charges on vulnerable groups: the case of Kibwezi in rural Kenya. Social Science \& Medicine 1995, 41:829-835.

7. Haddad S, Fournier P: Quality, cost, and utilization of health services in developing countries: A longitudinal study in Zaire. Social Science \& Medicine 1995, 40:743-753.

8. Ensor T: Informal payments for health care in transition economies. Social Science \& Medicine 2004, 58:237-246

9. Russell S: The economic burden of illness for households in developing countries: a review of studies focusing on malaria, tuberculosis, and human immunodeficiency virus/acquired immunodeficiency syndrome. Am J Trop Med Hyg 2004, 71:147-155.

10. Kruk ME, Mbaruku G, Rockers PC, Galea S: User fee exemptions are not enough: out-of-pocket payments for 'free' delivery services in rural Tanzania. Trop Med Int Health 2008, 13:1442-1451.

11. Goudge J, Gilson L, Russell S, Gumede T, Mills A: The household costs of health care in rural South Africa with free public primary care and hospital exemptions for the poor. Tropical Medicine \& International Health 2009, 14:458-467.

12. Nabyonga J, Desmet M, Karamagi $\mathrm{H}$, Kadama P, Omaswa F, Walker $\mathrm{O}$ : Abolition of cost-sharing is pro-poor: evidence from Uganda. Health Policy Plan 2005, 20:100-108.

13. Wilkinson D, Gouws E, Sach M, Karim SS: Effect of removing user fees on attendance for curative and preventive primary health care services in rural South Africa. Bull World Health Organ 2001, 79:665-671.

14. Witter $S$, Adjei $S$, Armar-Klemesu M, Graham W: Providing free maternal health care: ten lessons from an evaluation of the national delivery exemption policy in Ghana. Global Health Action 2009, 2.

15. Mpembeni RN, Killewo JZ, Leshabari MT, Massawe SN, Jahn A, Mushi D, Mwakipa H: Use pattern of maternal health services and determinants of skilled care during delivery in Southern Tanzania: implications for achievement of MDG-5 targets. BMC Pregnancy Childbirth 2007, 7:29.

16. National Bureau of Statistics, ORC Macro: Tanzania Demographic and Health Survey 2004-2005. Dar es Salaam, Tanzania: National Bureau of Statistics, Tanzania; 2005.

17. Pitchforth E, van Teijlingen E, Graham W, Fitzmaurice A: Development of a proxy wealth index for women utilizing emergency obstetric care in Bangladesh. Health Policy Plan 2007, 22:311-319.

18. WHO Statistical Information System. [http://www.who.int/whosis/en/].

19. United Republic of Tanzania Ministry of Health: Tanzania National Health Policy. 2003.

20. Kruk ME, Paczkowski M, Mbaruku G, de Pinho H, Galea S: Women's preferences for place of delivery in rural Tanzania: a population-based discrete choice experiment. Am J Public Health 2009, 99:1666-1672.
21. Vyas S, Kumaranayake L: Constructing socio-economic status indices: how to use principal components analysis. Health Policy Plan 2006, 21:459-468.

22. Schellenberg JA, Victoria CG, Mushi A, de Savigny D, Schellenberg D, Mshinda H, Byce J: Inequities among the very poor: health care for children in rural southern Tanzania. The Lancet 2003, 361:561-566.

23. Filmer $D$, Pritchett $L$ : Estimating wealth effects without expenditure dataor tears: an applicaton to educaitonal enrollments in states of India. Demography 2001, 38:114-132.

24. Kakwani $\mathrm{N}$, Wagstaff $\mathrm{A}$, van Doorslaer $\mathrm{E}$ : Socioeconomic inequalities in health: measurement, computation and statistical inference. Journal of Econometrics 1997, 77:87-103.

25. Kakwani NC: Income inequality and poverty: Methods of estimation and policy applications. Published for the World Bank [by] Oxford University Press; 1980.

26. van Doorslaer E, Masseria C, Koolman X: Inequalities in access to medical care by income in developed countries. Cmaj 2006, 174:177-183.

27. Zere E, Mclntyre D: Inequities in under-five child malnutrition in South Africa. Int J Equity Health 2003, 2:7.

28. Makinen $M$, Waters $H$, Rauch $M$, Almagambetova $N$, Bitran $R$, Gilson $L$, McIntyre D, Pannarunothai S, Prieto AL, Ubilla G, Ram S: Inequalities in health care use and expenditures: empirical data from eight developing countries and countries in transition. Bull World Health Organ 2000, 78:55-65.

29. Steinhardt LC, Waters H, Rao KD, Naeem AJ, Hansen P, Peters DH: The effect of wealth status on care seeking and health expenditures in Afghanistan. Health Policy Plan 2009, 24:1-17.

30. Kruk ME, Goldmann E, Galea S: Borrowing and selling to pay for health care in low- and middle-income countries. Health Aff (Millwood) 2009, 28:1056-1066.

31. Skarbinski J, Walker HK, Baker LC, Kobaladze A, Kirtava Z, Raffin TA: The burden of out-of-pocket payments for health care in Tbilisi, Republic of Georgia. JAMA 2002, 287:1043-1049

32. Mrisho M, Schellenberg JA, Mushi AK, Obrist B, Mshinda H, Tanner M, Schellenberg D: Factors affecting home delivery in rural Tanzania. Trop Med Int Health 2007, 12:862-872.

33. Abbas B, Hanifi SMA, Farhana U, Shehrin M: Three methods to monitor utilization of healthcare services by the poor. International Journal for Equity in Health 2009, 8.

doi:10.1186/1475-9276-11-7

Cite this article as: Ferry et al: Equity of inpatient health care in rural Tanzania: a population- and facility-based survey. International Journal for Equity in Health 2012 11:7.

\section{Submit your next manuscript to BioMed Central and take full advantage of:}

- Convenient online submission

- Thorough peer review

- No space constraints or color figure charges

- Immediate publication on acceptance

- Inclusion in PubMed, CAS, Scopus and Google Scholar

- Research which is freely available for redistribution

Submit your manuscript at www.biomedcentral.com/submit
Ciomed Central 